\title{
Causes of Heterosexual People's Changing Attitudes Towards Lesbian, Gay, Bisexual, and Transgender Group
}

\author{
Yingqi $\mathrm{Li}^{1, \dagger, \mathrm{a}, *}$, Yunhan Wang ${ }^{2, \dagger, \mathrm{b}, *}$, Xinyue Zhang ${ }^{3, \dagger, \mathrm{c}, *}$ \\ ${ }^{1}$ School of English Studies\&Honors College, Shanghai International Studies University, 201620, Shanghai China. \\ ${ }^{2}$ International culture and communication department, Beijing City University, 100083, Beijing, China. \\ ${ }^{3}$ Canterbury School of Florida, Knowlton Campus, 33702, St.Petersburg, Florida. \\ *Corresponding author.Email: ${ }^{a}$ 0201101071@shisu.edu.cn, ${ }^{b}$ veronicaduo@sina.com, ${ }^{c}$ iriszhang2003@gmail.com \\ ${ }^{\dagger}$ These authors contributed equally.
}

\begin{abstract}
With the Lesbian, Gay, Bisexual, and Transgender (LGBT) community appearing in public pervasively, people's perspectives on this minority group are polarized. Even though some people have gradually established the perspective of tolerance and protection of LGBT people, discrimination against them still exists. In this paper, we aim to find the causes of Heterosexual people's changing attitudes toward LGBT groups. We present the hypothesis that the factors of changing ideas of heterosexual people toward LGBT people vary a lot, including films, TV series, news, real ambient examples, and social media. To test this hypothesis, fetch information from literature reviews, mostly online resources, and distribute an online survey through WeChat, a Chinese social media software, to people who belong to the Heterosexual group. Respondents were asked to answer ten multiple-choice questions related to their understandings and conversion of their attitudes. The results showed that external factors caused Heterosexual people to alter their attitudes in a wide variety, verifying our hypothesis. We hope that by studying the factors that influence the change of Heterosexual groups' attitudes towards LGBT. We can extract methods and measures tailored to local conditions to promote society to treat this minority group more equally. We also hope to study the acceptance of different modes of communication by different people, and then have a clearer understanding and comprehension of entertainment and media in cultural communication.
\end{abstract}

Keywords: LGBT group, Heterosexual people, media channels, changing attitudes.

\section{INTRODUCTION}

\subsection{Background}

According to the latest survey data from the Gallup Poll Center in the United States, from 2012 to 2016, the number of LGBT adults in the U.S. adult population increased from 8.3 million to 10 million. The proportion rose to $4.1 \%$, reaching a record high [1]. In the same way, LGBT groups in China are increasingly willing to disclose their identities and face their minor sexual orientation calmly. Hence, the relevant survey data shows that the number of LGBT people in China who have acknowledged special identity increases year by year. On May 24, 2017, the judicial authority of Taiwan passed a constitutional interpretation, and Taiwan became the first region in Asia to recognize same-sex marriage [2]. As soon as this bill came out to the public eye, it immediately caused a wave of discussions in various fields about whether same-sex marriage should be accepted. As the series of changes and developments are obvious to the public, most popular topics deeply hit traditional social stereotypes and mundane regulation in China. Although people have gradually established a mentality to face LGBT people and attempt to protect them, underlying discrimination against LGBT people still exists. On the one hand, the situation in the United States is not optimistic. In 2018, Gay and Lesbian Alliance Against Defamation released its fourth-year identification promotion report, which revealed the acceptance of LGBT people in the United States had shown a declining change. On the other hand, a recent 
survey led by the United Nations Development Program and Beijing LGBT Center is informative. The survey results showed that $11.1 \%$ of heterosexual participants reported being unable to accept LGBT family members. And for other social relationships, the rejection rate ranged from $2.1 \%$ to $4.1 \%$. Additionally, more than $10 \%$ of heterosexual participants showed strong repugnance of being close (in terms of relationships) to LGBT people and were against the policy that LGBT people were available to raise children [3]. These survey data manifests pre-existing phenomenon with discrimination and unequal treatment of LGBT people, which are related to the diversity of national social culture and equity of humane civilization.

\subsection{Literature review}

Based on the topic of LGBT people, many scholars in different academic fields have already researched to explore the motivation of discrimination's changing towards LGBT people. One prominent research has shown that there are probably four aspects of factors that determined the changing attitude towards LGBT groups. Personal comprehension of LGBT people, contact with LGBT people, diverse religion of the participants, and media effect from society constitute the changing causes. Those that subscribe to the view that homosexuality is adopted by choice are less accepting because a choice is viewed as internal and controllable. In contrast, those who believe homosexuality has a biological origin hold more positive attitudes toward homosexuals [4]. Studies in this research show that endowed with the detailed biological explanation of sexual orientation, heterosexuals hold positive attitudes toward the LGBT group. While differences that result from hormones and genes interacting with developing brain cells are believed to be the basis of sex differences in the brain, people are prone to change the attitude towards the LGBT group [4]. Contacting with LGBT people more frequently, heterosexuals are enabled to broaden their insights and confront previous discrimination as realizing the inaccuracy of the past. Relationship and connection have been indicated to significantly influence overall attitudes toward LGBT people in a positive direction [4]. Research also undergoes that the more religious individuals are, the more prone they will be to initial negative attitudes. Religion is viewed as promoting resistance in changing attitudes toward LGBT people as well [4]. In some cases, the authentic evidence from media bout the cultural and social similarities between themselves and LGBT people will motivate them to abandon past stereotypes that display their attitudes and behaviors [4]. However, media effect from society has been generally refuted by scholarly research due to the uncertain bidirectional influence.

\subsection{Importance and purpose}

China contains the world's largest LGBT population without embracing them. LGBT people maintained an invisible role in China over more than 10 years [5]. While traditional Chinese culture regards adequate future generations and a prosperous family tree as one of the primary standards for success, it is the stubborn stereotypes formed through family education that oppressed the LGBT group. According to the exertion of the one-child policy in China, fewer heterosexuals show respect and approval to LGBT people. For the sake of concepts from ancient China and compulsive policies in modern China, there is little promotion and appeal for LGBT people. Furthermore, discrimination against them has wide implications in all aspects of society. For instance, cognitive distortions and absent sexual education from an early age are barriers to providing against sexually transmitted diseases, including HIV [6].

In the traditional perception firmly believed by most people, LGBT is usually excluded. However, with the rapid development of society, cultures become increasingly diversified, namely different values collide with each other. Secular concepts inevitably are impacted by the combination of them while people will gradually pay attention to minorities who have been neglected and rejected. Especially on account of the boom of self-media and the rise of various social media such as Weibo, WeChat, and Zhihu and the influence of some literary works, LGBT people are getting more and more attention. We must focus on the changes in attitudes of heterosexuals towards LGBT people, which can reveal the process of the diverse social civilization and offer profound inspiration to the construction of an equal society.

In a society with a tight connection between each part, the opinions generally acknowledged have a deeprooted influence on people's ideas. This kind of social ethos, which takes the mainstream value orientation of society as the universal criterion, makes Chinese people change themselves rather than change the society. As a result, obstinate social stereotypes exist, boosting more pressure and self-condemnation to LGBT people and dominating the living space of the LGBT community. We hope that by exploring the factors that influence the change of heterosexual attitudes towards LGBT people, we can obtain measures tailored to local conditions to promote society to treat them more equally. We also hope to study the acceptance of different modes by different people, and then have a clearer comprehension of entertainment and media in cultural communication.

After the brief introduction in the first section, detailed information, including the survey methods, explanation of the process, and the morality of our study, are presented in the second section. Additionally, the 
third section on the neck of it manifests profound analyses on the survey together with core points of the results. At last, the final section summarizes the whole project to attain a conclusion of the topic and gives readers an insight into potential problems and wider possibilities of the solution. In addition, in the end, all the references mentioned in the paper are placed.

\section{RESEARCH METHOD}

The survey method is our main way to collect data for this research in this paper. Since the questionnaire is very convenient for us to gather a large amount of data quickly and effectively, we can also conduct data analysis based on the survey results, which can improve the authenticity of our conclusions.

We designed a total of ten questions in the survey. We designed the questionnaire questions on the shared document and summarized all the questions into three types. The first type is related to the basic information of the respondents. The second type is about the respondents' attitudes towards the LGBT community. The last type is about whether or not they have conversion attitudes towards the LGBT community caused by external factors. For the survey, we set single choice and multiple-choice questions to help us get a deep understanding of the subjective and objective thoughts of the interviewees.

We used the questionnaire survey in "Questionnaire Star" through Wechat, a Chinese social media. The interviewees can fill the survey online by scanning the QR code, making it possible to organize the data validly. We collected 124 questionnaires. The respondents included all types of people of different ages, genders, and regions.

\section{RESULT AND DISCUSSION}

In this section, we divide our argument into three separated essential dimensions. Heterosexual People's Attitude Toward the LGBT Group, how the variety of media channels influence people's minds, and factors of Heterosexual people's changing ideas.

\subsection{Heterosexual People's Attitudes towards LGBT Community}

With the rapid progress of the times, the LGBT group appears more pervasive in our daily life, but people's attitudes are not uniform. Even though there are still a minority of unacceptable people to the LGBT group, the perceptions of the majority group are inclusive. This part will analyze people's attitudes towards LGBT groups and the changes in people's attitudes towards LGBT groups by combining the data and references we have collected.
According to Table 1, more than half of the 124 samples support the LGBT community, and people show a supportive and optimistic attitude towards the LGBT community. People's attitude towards this minority group is becoming more tolerant and understanding. According to Bowman, nonhomosexuals have a tolerant and open attitude towards the LGBT community [7]. However, up to $38.71 \%$ of our respondents revealed that they do not recognize this community and are mostly neutral in their attitude, which indicates that people's understanding of the LGBT group is still low. Such lack of knowledge leads to people's biased judgment that their attitude towards the LGBT group is not balanced. In our survey samples, only a limited number of respondents have an antipathy and aversion to LGBT groups.

Table 1 Attitudes toward the LGBT community

\begin{tabular}{|c|c|c|}
\hline Option & Number & Proportion \\
\hline A. Very supportive & 66 & $53.23 \%$ \\
\hline B. Do not understand & 48 & 38.71 \\
\hline $\begin{array}{c}\text { C.Dislike or } \\
\text { discriminate against it }\end{array}$ & 10 & $8.06 \%$ \\
\hline Fill in the number & 124 & \\
\hline
\end{tabular}

Nevertheless, various parts of the world have notably diverse attitudes towards LGBT people. The West is more equitable to LGBT people, and most countries have agreed to same-sex marriage. While attitudes in the Middle East are adverse. According to $\mathrm{Li}$ Yinhe, one of China's leading sociologists, homophobia is still a powerful enemy of reason [8]. This shows that there are still many homophobes who hate the LGBT community in China in addition to our survey samples. However, we believe that with the passage of time, the development of society, and the improvement of people's ideological consciousness, such fears will gradually disappear.

In China, more TV dramas and movies related to the LGBT community, especially themes of homosexuality, arise in the market. According to the Baidu search engine, China created seven TV shows about homosexuality in 2020, six more than in 2019. [9, 10].

At the same time, as shown in Table 2, people who watch movies or TV series associated with LGBT prone to have perspectives that are mostly unaligned. This result demonstrates that when people treat a minority group like LGBT, they think that the existence of this group is normal, and they no longer think that they or their behaviors are niches, special or novel. Further, approximately $37.1 \%$ of the respondents are more 
progressive, suggesting that these people are broadminded to the LGBT group. Subsequently, only $4.84 \%$ of people show distinctive disgust toward the LGBT group and not accept this kind of abnormal heterosexual relationship. In this case, they obtain relative traditional and conservative ideas.

Table 2 People's attitudes when they see LGBT segments on TV series or in movies

\begin{tabular}{|l|l|l|}
\hline Option & Number & Proportion \\
\hline A.Dislike it & 6 & $4.84 \%$ \\
\hline $\begin{array}{l}\text { B.Have some } \\
\text { criticism about it }\end{array}$ & 15 & $12.1 \%$ \\
\hline $\begin{array}{l}\text { C.Neutral } \\
\text { D. Support to speak }\end{array}$ & 46 & $45.97 \%$ \\
\hline up for them & 57 & $37.1 \%$ \\
\hline Fill in the number & 124 & \\
\hline
\end{tabular}

\subsection{Media channels}

Powered by advanced technology, the way people get information is more diversified. Extracted results from the survey data we collected from our respondents, how most heterosexual people obtain information about the LGBT community vary a lot, including social media, films and TVs, and even real experiences. This part will discuss how these different modes of communication affect the non-LGBT community's perception toward LGBT people.

According to Table 3, 42\% of respondents in our survey have the interests to browse information linked to the LGBT community to some extend.

Table 3 The frequency for people to learn information about the LGBT community

\begin{tabular}{|l|l|l|}
\hline Option & Number & Proportion \\
\hline A.Always & 22 & $17.74 \%$ \\
\hline B.Sometimes & 53 & $42.74 \%$ \\
\hline C.Rarely & 31 & $25 \%$ \\
\hline D.Never & 18 & $14.52 \%$ \\
\hline Fill in the & 124 & \\
number & & \\
\hline
\end{tabular}

In addition, as depicted in Table 4 the way people get information about LGBT groups is primarily covered by social media.

Table 4 People's most frequent ways to get information about the LGBT Community

\begin{tabular}{|c|c|c|}
\hline Option & Number & Proportion \\
\hline A.Social media & 88 & $70.97 \%$ \\
\hline $\begin{array}{l}\text { B.Entertainment(like } \\
\text { film or TV drama) }\end{array}$ & 74 & $59.68 \%$ \\
\hline $\begin{array}{l}\text { C.Real ambient } \\
\text { example }\end{array}$ & 68 & $54.84 \%$ \\
\hline D.Other ways & 26 & $20.97 \%$ \\
\hline Fill in the number & 124 & \\
\hline
\end{tabular}

Despite the fact from Table 4 that people may use social media less frequently, it is still a major way for people to acquire information. The social media that we are familiar with includes Weibo, Wechat, Twitter, YouTube, Zhihu, etc., effectively affecting people's thinking potential. Therefore, the LGBT community can be acknowledged by the general public. Many LGBT groups use these social media to inform their own stories and their perception of their identity. Thanks to the widespread dissemination of social media, it is now possible for more people to draw attention to minority groups. The more LGBT groups dare to take a stand on social media, the more people will alter their attitudes toward this minority group. It is indeed the case since people tend to follow the trend that most people consent to. Like the herd mentality, people's behaviors or beliefs are consistent with the group to which they belong.

The second significant method that people establish messages about the LGBT community is through some real ambient examples, like examples of the LGBT community. From this aspect, we can associate this finding with the one in a particular literature review. One cause for non-LGBT people to change their attitudes toward the LGBT community is contacting people who belong to the LGBT group [4]. When LGBT people surround people, they became more effortlessly develop sympathy because their acquaintances are members of the minority group. Also, people indeed start to have some emotional resonance with their LGBT friends from the bottom of their hearts. When we reach out to another human being, we have no control over our emotional interaction [11]. In this case, people will gradually begin to understand this group and even begin to admit them. 
Third, films and TVs are indispensable ways for people to retrieve information and switch their attitudes. As the LGBT community emerges more often in people's daily lives, many movies and TV dramas involve LGBT content, especially the topic of homosexuality. Through these two channels, people will receive many descriptions and insights about the LGBT group and deepen their impression of this minority group. We will also unearth that thematic designs in movies and TV series have made more people who were previously reluctant to accept, understand and treat LGBT groups incidentally become more endorse them. The rudimentary function can explain this specific phenomenon that entertainment has, potentially shaping or influencing people's opinions. When people watch films and TVs, we do not possess the intention/consciousness to explore erudition from watching series. Still, when watching those films or TV series, it can feasibly change our ways of thinking without entertainment, expressing we will learn something from them. One study mentions that mass media entertainment does affect our characters, behaviors, and attitudes [12]. Meanwhile, another explanation for this is the function that role model has in the films and TVs. It is widely known that role models always propels the popularity of certain things. Suppose role models act as members of LGBT groups in the movies or have some actions that support LGBT groups. These will enable more people to change their negative thoughts about the LGBT group. Since the effect of role models is far-reaching in public so that it can be assumed that more people will have an equal perspective of the LGBT community because fans will be more disposed to chase or trust certain concepts of their role models[13].

\subsection{Factors of changing ideas}

Based on our group research discovering the process and causes of heterosexual changing attitudes towards LGBT people, we analyze diverse factors that play an indispensable role. We find that the pre-existing and potential influence on common perception is basically divided into three parts - social culture, authority, and economy. The following analysis and Interpretation respectively elaborate the foundation together with the principle of them.

According to Table 5, the data shows that people will change ideas through positive promotion in social media.

Table 5 Impact assessment on positive advocacy in social media

\begin{tabular}{|l|c|c|}
\hline Option & Number & Proportion \\
\hline A.Will be affected & 78 & $62.9 \%$ \\
\hline B.Will not be affected & 46 & $37.1 \%$ \\
\hline Fill in the number & 124 & \\
\hline
\end{tabular}

As shown in Table 6, it discovers the fact that most people will be influenced by surrounding real experiences.

Table 6 Impact assessment on ambient LGBT people

\begin{tabular}{|l|l|l|}
\hline Option & Number & Proportion \\
\hline A.Will be affected & 81 & $65.32 \%$ \\
\hline B.Will not be affected & 43 & $34.68 \%$ \\
\hline Fill in the number & 124 & \\
\hline
\end{tabular}

Considering Table 7, we find that perspective from ambient people is another element determining the trend for people's attitudes.

Table 7 Impact assessment on ambient supporting attitude

\begin{tabular}{|l|l|l|}
\hline Option & Number & Proportion \\
\hline $\begin{array}{l}\text { A.Will be } \\
\text { affected }\end{array}$ & 83 & $66.94 \%$ \\
\hline $\begin{array}{l}\text { B.Will not be } \\
\text { affected }\end{array}$ & 41 & $33.06 \%$ \\
\hline Fill in the & 124 & \\
number & & \\
\hline
\end{tabular}

In brief, the common result of three tables is that people's attitudes toward LGBT group will be modified when the information of the LGBT community are exposed more frequently on multiple routes. Due to the rising internet and close connection between people, social media, real experiences, and the environment are essential elements driving the significant alternative, even revolutionary events.

Among all the categories of information transportation in social media, news reports play a formal and vital role for the sake of appropriate guidance to the public. As is known to all, the main task of the news report is to warn about real events considering the current cultural trends and traditional cognition of the country. As the herd mentality shows, people tend to be influenced by the outside world, especially the majority group. However, the common perception of heterosexuals mainly springs from the social culture. As China traditionally emphasizes the harmony of yin and yang, homosexuality has been a marginalized community for a long time. In most people's vision, homosexuality is almost connected with words such as ugly and sin. In the past, the image of homosexuality in the public's mind was always associated with concepts such as "immorality", 
"abnormal", and "sexual perversion", and was even treated as guilty. Naturally, news dissemination, whose mission is to reflect changes in real life, also keeps pace with society. The issue of homosexuality seems to be completely forgotten in news reports [14]. The British scholar Graham believes that the traditional cosmology finalized after $250 \mathrm{BC}$ was ordered by arranging a single chain of 'Yin' and 'Yang' into binary oppositions. He added that the binary opposition constituted by the corresponding relationship between Yin and Yang undoubtedly occupies a central position in Chinese culture [15]. Since the "Yin with Yang into complementarity" this model has never been questioned as a prerequisite for all inferences, it is also, in fact, becoming an effective rational tool for people to unify their thinking. This traditional cultural concept has long been rooted in people's thinking, making any sexual orientation that is not heterosexual become people's target. However, since ancient times, China has still admired a kind of "the golden mean" culture, which means that every social behavior beyond its role will be rejected. Therefore, in the traditional culture that advocates "the golden mean" and tries to achieve social harmony with the "Yin and Yang into complementary" mode as the background, any concepts related to system reform or social development are difficult to be considered [16].

Table 8 demonstrates nearly twice as many people who will be influenced by relevant government policies as those who will not be affected. Hence, the policy, as well as similarly authoritative propaganda, strongly hit people's minds.

Table 8 Impact assessment on publishing supportive policy of foreign countries

\begin{tabular}{|l|l|l|}
\hline Option & Number & Proportion \\
\hline A.Yes & 76 & $61.29 \%$ \\
\hline B.No & 48 & $38.71 \%$ \\
\hline Fill in the number & 124 & \\
\hline
\end{tabular}

Legally speaking, so far, China has not explicitly prohibited the protection of the rights of LGBT. Their rights are still in the zone between legal and illegal, and the protection of rights is in an uncertain state [17]. There was an ambiguous conviction for homosexual behavior in the "crime of hooliganism" in Chinese law in the Qing Dynasty. Modern people often believe that Article 5 of the Marriage Law stipulates that the term "male and female" in "marriage must be completely voluntary between the man and the woman" means that China does not recognize marriages of the same sex. However, with the development of the times and the advancement of people's cognition, homosexuality cannot be ignored for a long time. Sooner or later,
Chinese people will have to make their judgments on it from the legal level. Therefore, the interests of LGBT groups have been paid more and more attention to inlaws and regulations. From a long-term perspective, based on guaranteeing the basic rights of citizens, the law should bear the responsibility of establishing equal public knowledge through authoritative bills and regulations and safeguarding the basic dignity of people.

In addition, the public's fear and prejudice against LGBT originate from humans' innate rejection and avoidance of diseases. Intimacy between homosexuals is the cause of many diseases, including terrible AIDS. The breeding of diseases will bring people's pessimistic reveries, but the economic crisis caused by AIDS is why the entire society rejects LGBT. The impact of AIDS on China's total economy during the period 2006-2010 is mainly reflected in the partial or complete loss of individual human resources of patients, and secondly in the impact on agricultural productivity and the resulting loss of GDP. It is estimated that the total loss may exceed 370 billion yuan [18]. In addition, the increase in LGBT groups also means a huge impact on the country's fertility rate. Although the birth rate reduces human capital and material capital, which hinders economic growth is not obvious in China, it still exists [19]. Therefore, the development of LGBT groups may be impeded by many factors, including economic factors.

\section{CONCLUSION}

LGBT, as a minority group, still suffers from unfair treatment and a vague future in the recent era, which is a kaleidoscope yielding many potential opportunities together with difficulties. The negative-oriented public opinion and increasing pressure from non-LGBT people sharply reduced opportunities for heterosexuals to reexamine this group.

It can be suggested that there are three findings of our discussion. First, from the survey data we examined, it implies that people's attitudes towards LGBT are generally affirmative and supportive. Nonetheless, we have to admit that a handful of people's views towards the LGBT group are distasteful. Second, social media dramatically affects and shapes people's thoughts, potentially due to the herd mentality. Further, the more people are surrounded by LGBT people, the more easily people cultivate sympathy. Last but not least, both TV series and movies have impacts on people's opinions. Particular role models or celebrities can push to alter people's ideas for their extensive repercussions. Third, factors that are qualified to prompt thoughts of the LGBT community are miscellaneous. Internet sources and news reports advocate the Chinese traditional culture, fears of sexually transmitted diseases, and rejections. 
We found the theme of our survey is necessary for today's China. That is to say, the subject of sex education is scarce in the contemporary domestic. Likewise, people are reluctant to mention such an issue for descendants. Accordingly, we hope people can enhance awareness along with the endorsements to the minority group of LGBT.

In recent years, high-quality domestic research on public attitudes towards homosexual minorities and their influencing factors is still lacking. Few analytical studies have been completed due to national random sampling surveys. However, homosexuality exists objectively regardless of whether people see it in society. The visibility of the more tolerant society of homosexuality is high; the visibility of the society that is more discriminatory to homosexuality is low. The transparency of the gay community is the cornerstone that determines the development of this culture. Society needs to increase the acceptance of the LGBT community to give them a broader and more free development space. Therefore, for the sake of minority group like LGBT people the public are responsible for the cautious concern and consistent advocacy for the acceptation of them.

Our study centered on the factors and changing courses of heterosexuals' attitudes towards LGBT people, which prospect to alleviate the intense conflict between the two groups and promote the home-felt atmosphere for LGBT people. Furthermore, the equal society in sexual orientation will be accessible only when we make an effort to explore and research it.

\section{REFERENCES}

[1] China Daily.(2017). Survey shows that the number of gay people in the U.S. surpassed the 10 million for the first time.[Online] Retrieved May 3, 2021, from http://world.chinadaily.com.cn/201701/15/content_27959600.htm

[2] T. Fan.(2019). Taiwanese same-sex marriage is legal. [Online] Retrieved May 3, 2021, from https://www.chinairn.com/news/20190222/145648 367.shtml

[3] Y.Wang, Z. Hu, K. Peng, Y. Xin, Y. Yang, J. Drescher, R. Chen. (2019). Discrimination against LGBT populations in China.[Online] Retrieved May 3, 2021, from https://www.thelancet.com/journals/lanpub/article/ PIIS2468-2667(19)30153-7/fulltext

[4] Deese, Melissa A. and Dawson, Bryan L. (2013). Changing Attitudes toward LGBT Students: An Analysis of an Awareness Training Paradigm Aimed at Increasing Pro-LGBT Attitudes.
[5] T Burki, Lancet.(2017). Health and rights challenges for China's LGBT community.

[6] S. Zheng.(2018). The growing threat of China's HIV epidemic.

[7] M. Bao.(1979). New Zealand public attitudes towards homosexuality.

[8] Y. Li, H. Zheng.(2013). Public attitudes towards homosexuality and influencing factor.

[9] Baidu.(2020). China gay TV series of 2020. [Online] Retrieved May 5, 2021, fromhttps://m.baidu.com/s?from=1000539d\&word $=2020 \% \mathrm{E} 4 \% \mathrm{~B} 8 \% \mathrm{AD} \% \mathrm{E} 5 \% 9 \mathrm{~B} \% \mathrm{BD} \% \mathrm{E} 8 \% 80 \% \mathrm{~B}$ D\%Е7\%BE\%8Е\%Е7\%94\%B5\%Е8\%A7\%86\%Е5 $\% 89 \% \mathrm{~A} 7$

[10] Baidu.(2019). China gay TV series of 2019. [Online] Retrieved May 5, 2021, fromhttps://m.baidu.com/from=1000539d/s?word= 2019\%E4\%B8\%AD\%E5\%9B\%BD\%E8\%80\%BD $\%$ E7\%BE\%8E\%Е7\%94\%B5\%Е8\%A7\%86\%Е5\% $89 \%$ A7 \& sa $=$ tb\&ts $=0 \& t$ t $\mathrm{kt}=0 \& \mathrm{ie}=$ utf-

8\&rsv_t $=5 \mathrm{fbaKS} 8$ buTUfsnlNQdyet $\% 252 \mathrm{Fx} 1 \mathrm{WuF}$ qgtUzYcjPtHyP9s67VWu3NpjA3an6lo52XqE\&rs v_pq $=5646834403579816162 \&$ ss $=110 \&$ sugid=39 00583489824917973

[11] Hatfield, E., Cacioppo, J. T., \& Rapson, R. L. (1994). Studies in emotion and social interaction.Emotional contagion. Cambridge University Press; Editions de la Maison des Sciences de l'Homme.

[12] FEDERMAN, Joel (Ed.) 1998 National Television Violence Study.

[13] Lewen Wei, Arienne Ferchaud, Bingjie Liu. (2019) Endorser and Bodily Addressing in Public Service Announcements: Effects and Underlying Mechanisms.

[14] L. Deng.(2004). Deviant Love and MarriageHomosexuality and the face of the news media.

[15] A.C. Graham.(2003). Disputer of Tao.

[16] Y. Liang. (2007). An Analysis of the Thinking Mode of "Yin and Yang Complementation"_- A Combination of Traditional Cultural Resources in the Construction of a Harmonious Society.

[17] D. Han.(2016). Law Forum----Human Dignity, Tolerance and the Constitutional Protection of the Rights of Homosexuals.

[18] J. Li, H. Ren.(2007). Academia----The impact of AIDS on my country's macro economy from 2006 to 2010 .

[19] Y. Du.(2005). The formation of China's low fertility rate and its impact on long-term economic growth. 